\title{
Proposed metrics to measure quality: Overview
}

\author{
Anrudh K. Jain \\ Population Council \\ John Townsend \\ Population Council \\ Saumya RamaRao \\ Population Council
}

Follow this and additional works at: https://knowledgecommons.popcouncil.org/departments_sbsr-rh

Part of the Demography, Population, and Ecology Commons, Family, Life Course, and Society Commons, and the International Public Health Commons How does access to this work benefit you? Let us know!

\section{Recommended Citation}

Jain, Anrudh K., John Townsend, and Saumya RamaRao. 2018. "Proposed metrics to measure quality: Overview," Working Paper 3, prepared for the Measuring and Monitoring Quality of Care Project. New York: Population Council. 


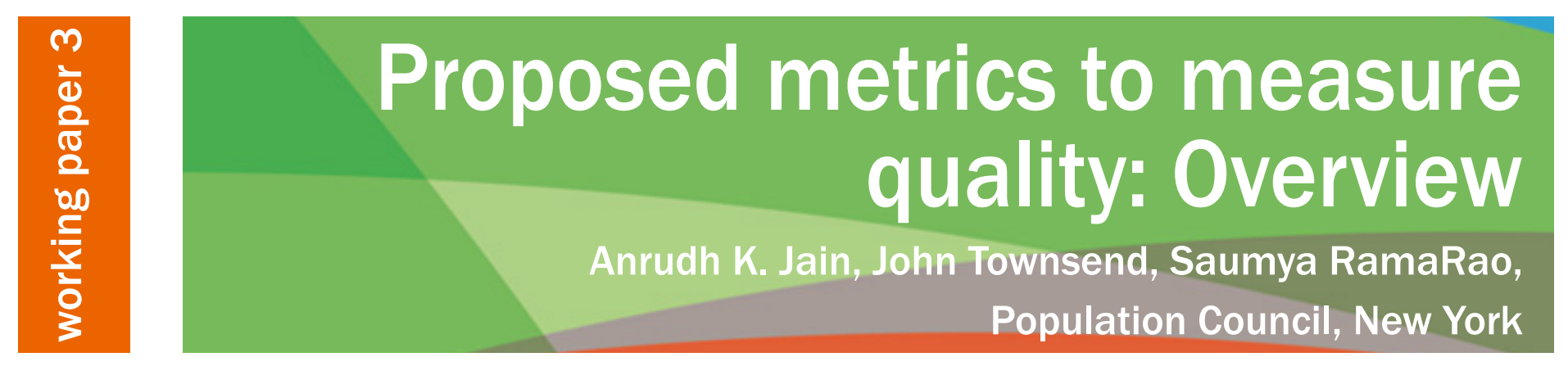

\section{As different types of indicators of quality are required for policy and program development, we propose a new set of measures to assess quality across different levels and settings.}

\section{ABSTRACT}

While the first quality of care framework in family planning was articulated over 25 years ago and a considerable amount of work has been done since then to measure quality in the context of routine service delivery. Yet, we do not have agreed upon indicators to measure quality that can be applied uniformly across different health systems and social contexts. The work done so far reflects the types of data available in developing countries. In this paper, we have taken a slightly different approach and used a common definition of quality from the outset. Indicators of quality are required for describing the nature of family planning services and quality of care offered by a health service delivery program, and for improving clients' experience and health outcomes. Additionally, indicators are needed for monitoring quality of care overtime in a single country (e.g., for quality improvement) as well as for comparing quality across countries (e.g., for understanding contraceptive discontinuation and unintended pregnancies).

Different types of indicators are needed to serve these different needs for policy and program development. Keeping these needs in mind, we propose a new set of measures to assess quality across different levels and settings.

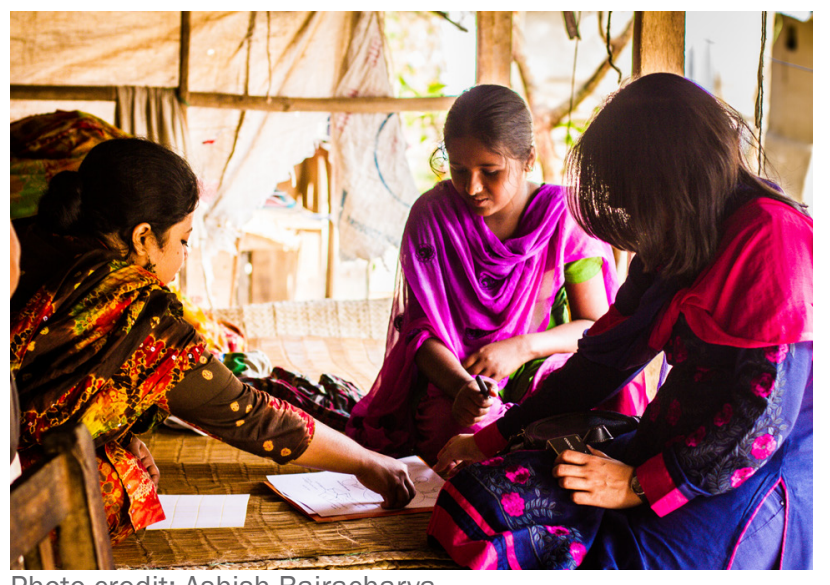

Photo credit: Ashish Bajracharya

\section{BACKGROUND}

More than 25 years ago, Bruce (1990) articulated a client-centered quality of care framework for family planning. Recognizing the important role of measurement in ensuring quality improvement, many efforts since then have been made to measure quality both in the context of research and routine service delivery. The methodologies and indicators used in these efforts have been reviewed by Tumlinson (2016), and RamaRao and Jain (2016). The main approaches used for data collection include: facility surveys (e.g. SA, QIQ, MLE, PMA2020, and SPA) ${ }^{1}$, cross-sectional surveys of individual women (e.g. DHS and PMA2020), and special studies conducted to assess the relationship between quality of care and reproductive health $(\mathrm{RH})$ outcomes (e.g. Koenig et al. 1997). The SA used four instruments of data collection (i.e., facility audit, provider interview, observation, and client exit interview), but the QIQ used all instruments except the provider interview. Given their cost and complexity, both SA and QIQ methodologies are no longer in

${ }^{1}$ SA: Situation Analysis; QIQ: Quick Investigation of Quality; MLE: Measurement, Learning, and Evaluation; PMA2020: Performance, Monitoring, and Accountability 2020; SPA: Service Provision Assessment; DHS: Demographic and Health Survey.

The Population Council conducts research and delivers solutions that improve lives around the world. Big ideas supported by evidence: It's our model for global change. popcouncil.org

\section{POPULATION COUNCIL}

Ideas. Evidence. Impact. 
common use, except in special studies. These methodologies were ostensibly replaced by the SPA, which is designed and managed by the Demographic and Health Survey (DHS). The SPA uses the same four instruments of data collection as the SA, and it has been conducted in about 15 countries. In addition, under the Family Planning 2020 (FP2020) initiative, PMA2020 collects facility-level data through facility audits in eleven countries.

Beginning with Kenya in 1989, SA was used extensively to describe the quality of family planning services in several sub- Saharan African (SSA) countries (Miller et al. 1991). For example, Askew et al. (1994) used these data to create over 40 indicators classified under various elements of quality. Mensch et al. (1994) used these data to describe the functioning of sub-systems of family planning in Nigeria, Tanzania, and Zimbabwe. Miller et al. (1998) listed 28 indicators for infrastructure and facility readiness, and 36 indicators for quality of care. Recognizing that there was a greater utility and lower cost in using a smaller number of indicators, the QIQ methodology developed by Tulane University reduced the number of indicators to 25 for which data were collected to describe quality in Ecuador, Turkey, Uganda, and Zimbabwe (Sullivan and Bertrand 2000).

Special studies also used data collected through SA to assess the effect of targeted interventions on quality of care. For example, Costello et al. (2001) used data on 24 items collected through exit interviews to assess the effect of a provider training intervention on quality of care received by clients in the Philippines. Data collected through SA has also been used to study the effect of quality on contraceptive use, method continuation, and unwanted fertility (Mensch et al. 1997, RamaRao et al. 2003, Jain et al. 2012). Tumlinson et al. (2015) used data from the MLE (Measurement, Learning and Evaluation) project to assess the relationship between quality of care and contraceptive use in urban Kenya. These studies using facility surveys primarily tried to measure each of the six elements of quality articulated in the Bruce framework separately; some of them then also combined these elements to estimate an overall index of quality.

Recently, with a focus on developing more valid indices, SPA data have been used to describe the quality of care in routine care in Kenya, Namibia, and Senegal (Wang et al. 2014) and in Ethiopia (Tessema et al. 2016). These studies used factor analysis to explore diverse elements in structure, process, and outcome indicators of quality. Mallick et al. (2017) created summary measures of quality of services and quality of care from SPA data by using three methods of combining individual indicators-simple additive, weighted additive,and principle component analysis. PMA2020 data are also being used to study the relationship between quality and contraceptive use.

Tumlinson (2016), after reviewing much of this information, concluded that 'In addition, within studies investigating the quality of family planning services there is great diversity in how quality is defined and which elements of quality of care are considered most important, with no agreed set of indicators. Inconsistent definitions of quality pose a challenge to summarizing results of studies investigating quality of care in FP programs.'

Indicators used to measure quality in the past were constrained by the availability of data collected through facility and cross-sectional surveys. The purpose of this paper is to propose metrics to measure quality that go beyond the currently available data with the anticipation that some of the data required can be collected in future studies and eventually incorporated in national health information systems. Some of these data can be incorporated in the ongoing data collection activities such as DHS, SPA, PMA2020, and Health Management Information Systems (HMIS). The indicators proposed below are based on a common definition of quality and a common framework to measure quality. It is recognized that given the complex nature of quality and health systems, any one indicator, or even a small set of indictors, is not sufficient to be used for all purposes.

\section{DEFINING QUALITY}

Bruce (1990) articulated a client-centered quality of care (QoC) framework consisting of six conceptual elements: Choice of contraceptive methods, Information given to clients, Technical competence, Interpersonal relations, Follow-up/ continuity mechanisms, and appropriate Constellation of services. Following Donabedian's (1988) quality framework, Bruce (1990) also distinguished three points from which to view quality: structure of the program, service-giving process, and outcome of care (see Figure 1). While all the six elements are important at both structure and process levels, it has been difficult to operationalize and measure them at each of these two levels separately. Each element can be mapped at least at one level and some at both. One would expect that both would have an effect on the outcome of care for clients, albeit through somewhat different pathways, e.g., knowledge of requirements for direct client care versus management of the supply chain to ensure supplies.

The term quality has since been used in many frameworks for health, reproductive health, and family planning. Jain (2017a) proposed the following five modifications to the Bruce's QoC framework to better align it with the treatment of quality in rights-based approaches to care and to facilitate the operationalization and measurement of quality in the future.

No change was suggested in the elements of choice and constellation of services. The first modification is that the element of providers' technical competence has been broadened to explicitly include competency in providing the method chosen, insertion and removal of clinical methods safely, compliance with infection prevention practices, and communicating effectively with clients. The second modification is that the element of information given to clients is replaced by information exchange with clients to reflect two-way communication with providers in the clinical 
Figure 1: Operationalizing Quality

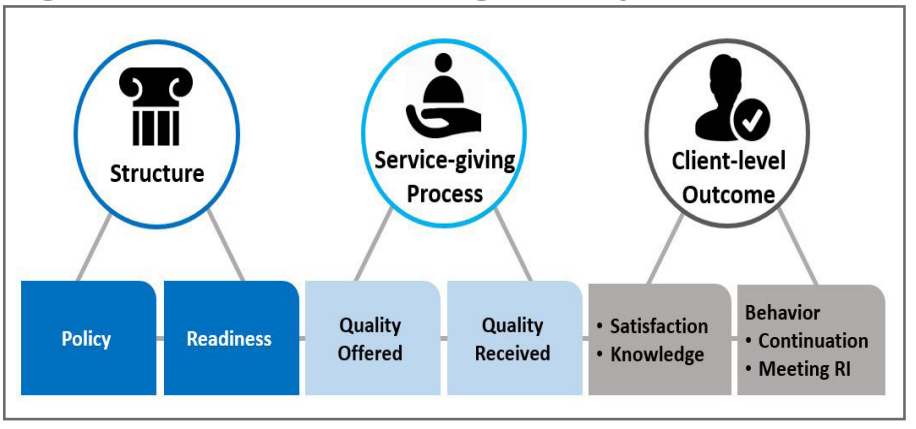

setting. The third modification is that the element of followup is operationalized through information exchange at the point of care. The fourth modification is that the element of interpersonal relations is expanded to explicitly include the treatment of clients with dignity and respect, and ensuring their privacy and the confidentiality of the consultation and related records. The fifth modification is to map these six elements on structure and process.

The distinction between structure and process is similar to the distinction sometimes made between quality of services and quality of care. Structure or quality of services includes two components: 1) policy-level intention to provide an explicitly stated standard of care (both in content and quality) by the health system, and 2) the readiness of the services to offer the intended standard of care. The service-giving process refers to the extent to which clients are offered and receive the intended standard of care according the service they require.

The task of operationalizing, improving, and measuring quality can be facilitated if it is recognized that some the elements of quality in the original as well as modified framework are more appropriate at the structure level to ensure the readiness of services. These include, choice of methods made available, availability of trained and competent providers, availability of space to ensure privacy and confidentiality, and availability of other appropriate $\mathrm{RH}$ services. The other elements of information exchange and interpersonal relations, broadly categorized as clientprovider interactions (CPI), are more appropriate at the process level. It should be mentioned that all elements of quality can be operationalized through $\mathrm{CPI}$ at the point of care. For example, a facility may be ready to provide choice among methods to clients but it is the provider who will make it possible through information exchange for the client to select a method appropriate to the client's needs, interests and circumstances. For this reason, we have not included informed consent as an explicit element of quality. However, the issue of informed consent may be more appropriate in some settings in the case of permanent methods. We also hypothesize that it is the clients' experiences that will determine their future behavior including return to health facilities, adherence to contraceptive use (including switching methods, providers, or service sites), or referring others to these services.

\section{PROCESS OF IMPROVING QUALITY}

The four levels included in defining structure and process have also been used to describe the process of improving quality (Bruce 1990, Jain et al. 1992). Instead of setting a standard of quality, Jain et al. (1992) recommended an interactive and explicit process to set and review standards over time, which should be made operational through on-going iterations that include policy makers, program managers, providers, and clients thus reflecting a Continuous Quality Improvement (CQI) approach. The process should seek to answer the following four questions:

1. What quality of care does a program intend to offer?

2. What quality of care is a program ready to offer?

3. What quality of care is offered to clients?

4. What quality of care are clients receiving?

The process for improving quality thus includes the following steps:

First, measuring the level of care program intends to offer, ready to offer, offering to clients, and the care clients are actually receiving. Second, determining gaps between these measures of quality, i.e., between intention and readiness, between readiness and care offered, and between care offered and care received. Third, using these gaps to identify interventions needed to ultimately improve care received by clients. Within the broader health system context, the effort to enhance quality of family planning is more likely to be successful if the effort also incorporates other related service areas of reproductive, maternal health and STI prevention information and treatment as needed.

To improve quality, it needs to be first measured. To begin with the program managers and policy makers should be explicit about the standard of care they wish to offer to their clients by type of provider and level of care of the health system. The answers to the remaining three questions can be obtained by using any methodology similar to SA, QIQ, and SPA. For example, the readiness of a service delivery point (SDP) can be assessed by using facility audits and with provider interviews; the standard of quality actually offered by using observations of client-provider interactions by a thirdparty observer or by using mystery clients, and the standard of care received or experienced by clients can be assessed by using client exit interviews. It should be noted that technical competence of a provider can only be assessed by a qualified independent observer (often someone with a related clinical background) who also is familiar with the standard of care desired. We must assume that all the observation methods are subject to measurement error both due to the differences in required care, the skill of the specific provider as well as the nature of the exchanges between providers and clients.

\section{METRICS TO MEASURE QUALITY}

Measuring quality is important for improving quality as well as for monitoring quality for routine program operations. The 
modified framework mentioned above is used to propose the following metrics to measure quality in its diverse manifestations or purposes. The selection of an indicator or a set of indicators, however, will depend upon the purpose of its use, because each indicator has to align with the objective (RamaRao and Jain 2016). In general, indicators based on facility surveys can be used to identify gaps and take subsequent actions to improve quality at the facility level. Acknowledging different levels and complexities of facilities within health systems, indicators based on cross-sectional surveys can be used to monitor quality as experienced by residents of a community or geographic area including users and potential users of services. Longitudinal studies can be used to assess the effect of care received on appropriate reproductive health outcomes over time. And HMIS should be able to detect whether services are being provided by the health system at the level of standard required, and by its nature would include multiple levels of care.

\section{Policy indicators of quality}

While national program managers and policy makers often acknowledge the importance of quality, they are rarely explicit about the standard of care they wish to provide, given the diversity of human and institutional resources available at any time and place. Policy documents may include broad statements about providing good quality services. For example, there could be a policy about whether a particular contraceptive method is approved for delivery in the program and who may be qualified to provide it. Policy documents may also include guidelines for training of service providers at different levels and guidelines for safe delivery of contraceptive methods and related services. However, these guidelines may not be available at the facility for consulting, on-site training, or continuing education of service providers. Hence, there is a need for a simple tool to explicitly derive policy intention based on existing policy documents and guidelines. The specific tool can be used in a group setting of program managers and policy makers to elicit their policy positions, recommended actions, and challenges to improve quality.

Appendix 1 includes an illustrative tool that can be used to solicit inputs from stakeholders in a country or program to identify attributes of high quality family planning services and to define the quality of care they intend to provide to their clients. A discussion of offering choice or offering a method to meet the needs of various groups of clients is particularly important to decide about the number and type of methods to be included in the program because contraceptive methods have different characteristics (Clark et al. 2017), and place different demands on supply chain and procurement systems.

\section{SDP readiness indicators of quality}

The quality of services or readiness of a service delivery point $^{2}$ (SDP) to offer services of a given quality is usually measured from data collected through facility surveys or audits supplemented by provider interviews. Table 1 lists close to 40 items included in various facility surveys and used by researchers in data analysis and characterization of structural levels of quality. While many of these items are required for the operation of the facility and may be used to estimate and characterize the level of quality of services, many of them such as the availability of electricity and water do not directly reflect the readiness to offer quality services specifically, although they may be required for infection prevention or clinical examinations. As a result, many researchers have started using factor analysis to reduce the number of items included in a composite indicator and increase their internal consistency.

We propose a slightly different approach that reflects the modified framework. As mentioned earlier, the elements of quality that are more appropriate to ensure the readiness of SDPs to provide quality services include: choice of methods available, availability of trained and competent provider, availability of space to ensure privacy, and availability of other appropriate $\mathrm{RH}$ services. SDP readiness indicators of quality should reflect these attributes. We propose four domains of SDP readiness, which can be combined to create an overall SDP readiness indicator of quality:

1. Ready to offer a choice of methods for the range of client needs

2. Ready to ensure safety and compliance with infection prevention practices

3. Ready to ensure appropriate client-provider interactions to understand client needs as well as provider requirements for care

4. Ready to offer other appropriate $\mathrm{RH}$ services requested or appropriate for the client.

The construction of an indicator for each domain would require data on many individual items that can be collected through facility audits supplemented by provider interviews. This information can be used first to create indicator of each domain and then an indicator of overall readiness. The overall indicator of SDP readiness can then be easily used to accredit a facility or SDP according to the quality of services it is ready to offer. We acknowledge that some lapses in readiness of an individual facility may be more system related, such as supply chain challenges and staff training and turnover, than related to that facility per se. However, we believe that these readiness indicators can measure and provide a snap shot of the readiness of the entire system to guide decision-making. Periodic repetition of the process will

\footnotetext{
${ }^{2}$ SDP includes fixed health facilities, community-based services, as well as pharmacies. We have used SDP and facility interchangeably. The indicators are proposed to keep health facilities in mind, because they provide services for multiple methods. These can be adapted for community-based services as well as pharmacies, which mostly provide services for short-term reversible methods (e.g. condom and pill).
} 
help to assess the effect of interventions, to monitor changes overtime as well as to ensure that an individual facility is not penalized for system failures, e.g., failure to supply required commodities. Many items required to create these structurelevel indicators may already be included in a country's HMIS. The feasibility of collecting the required information regularly through HMIS needs to be explored because it will help to create structure-level indicators and monitor quality regularly without undertaking facility surveys. Issues of data quality and aggregation of data with irregular or incomplete reporting will undoubtedly have to be considered.

We provide an example of the creation of an indicator of method choice, which is based on the procedure illustrated by RamaRao and Jain (2016). Method choice is sometimes measured by the number of methods available at a SDP and other times by a well-defined mix of methods or by the availability of particular methods for specific needs, e.g., emergency contraception or long-acting reversible contraception (LARCS). WHO guidelines suggest that to meet the diverse needs of many clients, family planning programs should make at least five types of methods available: emergency contraception, short acting reversible, long acting reversible, permanent, and method to protect against STIs. On the other hand, if the objective is to meet the needs of different groups of clients or the needs of the same client overtime, the list of methods included in the program could be more diverse to address the needs and preferences of the broader profile of clients. We propose two indicators of choice: 1) number of methods (count of all methods) available at a SDP, and 2) type of methods (count of five types of methods) available at a SDP.

The availability of a method often is measured by the availability (in stock) of commodities at a SDP. In contrast, RamaRao and Jain (2016) measured the availability of a method not only by the availability of commodity as is usually done, but also included information on the availability of required equipment, particularly for LARCs and permanent methods, and the availability of a provider trained to the standard of quality desired. However, for quality services, it is also important that the SDP be ready to offer removal services for clinical methods (e.g. IUD or implant) on demand.

RamaRao and Jain (2016) did not include this item in the creation of the availability indicator because they did not have this information. We propose that the availability of removal services on demand be also included in measuring the availability of a clinical method. Thus, we propose that the availability of a method is ascertained by the availability of the commodity, equipment required for insertion and removal of a clinical method (e.g. IUD and implant), and availability of a provider trained and competent in associated counseling, insertion, and removal of a clinical method safely and on demand. These requirements would vary depending upon the method. For example, there is no commodity required for permanent methods of contraception, i.e. for tubal ligation for women and vasectomy for men. For these methods, one needs to monitor only the availability of required equipment and the availability of trained and skilled providers in appropriate client-provider interactions (including counseling) and performing the procedure and follow-up safely. Given the permanent nature of the method, it would also be important for the provider to ensure that the client understand that the method is permanent and makes this choice voluntarily. In some contexts, it may be important to obtain the client's (or guardian's) informed consent, either verbally or in writing, prior to the procedure.

Using similar reasoning and procedures, items required to create an indicator to measure structure-level quality (or readiness for quality) at health facilities can be specified as follows:

\section{Ready to offer choice (number and type) of contraceptive methods}

- Availability of commodities (approved and unexpired)

- Availability of provider competent in insertion and removal of a reversible clinical method safely*

- Availability of equipment required for insertion/ removal of a reversible clinical method*

Ready to ensure safety and compliance with infection prevention practices*

- Availability of guidelines for correct medical procedures and infection prevention practices

- Availability of equipment and commodities required for infection prevention practices

- Availability of a competent provider to ensure compliance with guidelines for correct medical procedures and infection prevention practices

Ready to ensure appropriate client-provider interactions

- Availability of space to ensure audio and visual privacy

- Use of reliable systems for management of confidentiality of client records

- Availability of trained/competent provider in:

- Treating clients with dignity and respect

- Appropriate information exchange with clients (e.g. on needs, preferences and goals)

\section{Ready to offer other $\mathrm{RH}$ and $\mathrm{MCH}$ information or service which may be desired or required at the same time}

(* Applicable for clinical methods. It will be essential to consult national and WHO guidelines to define competency of a provider and creating a list of equipment and commodities required for safe provision of a reversible or a permanent method and ensuring infection prevention practices.)

It should be noted that all these domains and indicators are not applicable for services provided by community health workers and pharmacies, because in most cases, they provide services for short-term reversible methods (e.g. condoms and pills), orientation and referral. In these cases, one needs to ensure the availability of approved and unexpired commodities of assured quality and the provider trained in appropriate client-provider interactions. 


\section{Process indicators of quality}

Table 2 lists many of the items used in creating process indicators of quality by various researchers using facility and cross-sectional surveys. As might be suspected, there is tremendous diversity of strategy, content, and use of indicators. Costello et al. (2001), for example, used data on 24 items that reflected different aspects of client- provider interactions and created five indicators: needs assessed, choice of methods, information clients received, client felt she was treated well, and client felt well connected with services. RamaRao et al. (2003) and Jain et al (2012) used this information to create an overall index of quality. Sathar et al. (2005) used four domains of quality in Pakistan that characterized client-provider interactions: Salutation, Assessment, Help, and Reassurance (SAHR). Tumlinson et al. (2015) used data from the MLE project to create indicators of various elements of quality. Wang et al. (2014) used factor analysis and eight items from SPA surveys to create an overall process indicator of quality. While there is some overlap among items included by various researchers and items included in various sources of data, there is no uniformity in item or index development, context of use or appropriate nature for analysis.

The 2012 Family Planning Summit held in London reinvigorated interest in family planning and quality of care. Recognizing that quality has an important role in the achievement of goal set by the FP Summit, FP2020 has included a Method Information Index (MII) among its core indicators to measure progress. This index is based only on three questions asked from current users of contraception: were you told about other methods, were you told about side effects of the selected method, and were you told how to manage them. These three questions are usually collected in almost all ongoing facility and cross-sectional surveys. The MII index has been used to study differences among countries and changes overtime within a country (Jain 2016, FP2020). The simplicity of MII is an attractive feature of this indicator. However, we do not know the extent to which these three questions reflect the key elements of the service-giving process and the extent to which they can predict future service quality, contraceptive use and unwanted fertility.

The service-giving process (quality of care offered and received) defined in the modified framework includes appropriate interpersonal relations with clients and information exchange with them to facilitate selection of an appropriate method, effective use of the method selected, and ensuring continuity of use and care. Using this as a common framework, we propose the following four process indicators reflecting each of the four domains of quality in the modified framework:

\footnotetext{
- Respectful care (6 items)

- Method selection (8 items)

- Effective use of method chosen (5 items)

- Continuity of care (4 items)
}

The first domain reflects interpersonal relations, the second and third domains reflect method choice, and the fourth domain reflects follow-up mechanisms. It should be noted that the last three domains together reflect information exchange between providers and clients. Each of these correlated domains is made up of number of individual items; numbers shown in the parenthesis. Table 2 lists proposed items classified under each of these four domains.

We can create four different process domain indicators as well as one overall process indicator of quality by using all the proposed items. Factor analysis can be used to address the issue of inter-correlations among items and to select the number of relevant items, identify the number of domains (factors), and to construct an overall index of process quality. This type of analysis may also help in identifying additional questions that can be added to the creation of MII. For example, in the DHS, sterilized women are asked whether they were told the method was permanent. This question is not included in MII because there is no similar question asked from the users of reversible methods. To remedy this situation, Jain (2016) proposed that users of reversible methods be asked whether they were told that the method was temporary and about the possibility of switching the method selected.

Exact wording of questions to collect data may differ across different surveys, raising issues of both validity and reliability of measure. And clearly, the relevance and contribution of each item and domain may also vary by context. Many of these items may receive normative responses across societies and, if so, they can be deleted from the final list.

As mentioned earlier, the required data can be collected by using independent observers, mystery clients, and/or exit interviews. Research has shown that the quality of care identified differs depending upon the techniques used for data collection. The use of observers and mystery clients generates information about the behavior of the provider, i.e. the way a provider is treating a client and the information a provider is giving to a client. In contrast, the exit interviews generate information about how a client felt she was treated at the facility and the information she received or was given to her. The difference between the two is equivalent to the care offered by providers and that received by clients. These two quality estimates are sometimes also called as actual and perceived levels of quality. The quality of care actually delivered by providers or actual quality of care may be more useful in identifying gaps and improving providers' behavior and system support. The quality of care received or perceived quality may be more important than actual quality in determining clients' subsequent contraceptive use and fertility behavior.

\section{OUTCOME INDICATORS}

Bruce (1990) suggested measuring outcomes along a timeline in terms of clients' knowledge, behavior, and satisfaction. Client's knowledge outcome, according to Bruce, 
constitutes a nearer term outcome and can include clients' knowledge to use their method, knowledge of alternatives (including sources), and clients' willingness to return to the provider or refer others to the same site or provider. This articulation of knowledge outcome overlaps considerably with the indicators of service-giving process and the measurement of another outcome indicator-satisfaction.

A simple nearer term outcome indicator used in the past is whether or not the woman received the method of her preference. This indicator was also found to be associated in some studies with continuation of contraceptive use (Pariani et al. 1991). However, contraceptive discontinuation is also influenced by many factors beyond method preference including whether or not women discussed with their partners discontinuing a method or switching to another method (Barden-O'Fallon and Speizer 2011). Sometime, this indicator is included among the process items. However, this indicator should be calculated by comparing the preferred method stated at the beginning of interaction, its medical appropriateness, and the final method received.

Experience suggests that using one question about whether the client was satisfied with services solicits normative responses and more than 90 percent of women report being satisfied with the services received regardless of the actual quality delivered. This may reflect a courtesy bias or a reflection of the overall poor treatment received by women in other service spheres. Wang et al. (2014), using SPA data on 12 items, created an indicator of satisfaction. Many of these items, reflect the service-giving process and are included in process indicators of quality instead of an indicator of satisfaction. Other ways to measure satisfaction could include whether or not the client will return or refer a friend or family member to the same provider or SDP. It also appears that referral or intention to use a particular provider or facility may also elicit a normative response. Measurement and appropriate interpretation of satisfaction certainly requires additional work.

Another possible outcome indicator is the average contraception discontinuation rate. In principle, reproductive calendars included in the DHS can be used to estimate method-specific and all method discontinuation rates (Ali et al. 2012). However, the all method discontinuation rate is significantly affected by the method mix. These rates are estimated by using episodes of contraceptive use and not the women using contraception. Consequently, shorter episodes are over represented and they do not reflect the continuity of contraceptive use by a woman irrespective of the method used, i.e., they don't incorporate method switching. These issues can be addressed by estimating all methods and all segments discontinuation rates (see Blanc et al. 2002).
In terms of measuring longest-term outcome, an indicatorHARI, an acronym for Helping Individuals Achieve their Reproductive Intentions- was proposed in 1994 to measure success or failure of family planning programs with a reproductive health orientation (Jain and Bruce, 1994). It was estimated by using panel data from Peru (Jain 2001). HARI applied the principle of individual rights and well-being to the assessment of these programs. It measured two components: the achievement of an individual's reproductive intentions and the avoidance of severe health problems associated with clients' efforts to achieve their stated reproductive intentions.

The estimation of the first component required panel data in which reproductive intentions are stated and recorded at the beginning of the observation period and their achievements are measured subsequently during the observation period. The occurrence of serious health problems in the Peru example was measured retrospectively by an overnight stay in the hospital. This indicator, however, has not been used widely because of the requirement of panel data and because of relatively little contribution of serious health problems as illustrated by the Peru analysis.

A new outcome indicator proposed by Jain (2017b) is the percent of users who are successful in avoiding an unintended birth during, for example, five years prior to the interview. It relaxes the requirement of panel data and is similar to the first component of the HARI index, the achievement of reproductive intentions. It can be estimated from calendar data included in cross-sectional surveys.

The estimation of this indicator considers a period of, for example, 5 years prior to survey. Let t denote the time of survey. Whether or not a woman was using a modern method of contraception at (t-5), i.e., 5 years prior to survey is determined by using the reproductive calendar data. The period of exposure starts at that time (t-5) and ends with an interview. All segments of use, irrespective of the method used, and nonuse are thus included. The retrospective reports about most recent birth and the current pregnancy at interview being wanted, unwanted, or mistimed are considered in estimating the Success indicator.

These users are then divided into three groups based on whether or not they had any birth between $t$ and $t-5$; whether their most recent birth (including current pregnancy) was reported to be intended or unintended (mistimed and unwanted) at the interview: 1) those who had no birth between $t$ and $t-5 ; 2$ ) those whose recent birth (including current pregnancy) was reported to be intended, and 3) those whose most recent birth (including current pregnancy) was reported to be unintended. ${ }^{3}$

Success in avoiding an unintended birth between time t-5 and $t$ is measured by adding the first two groups and failure

\footnotetext{
${ }^{3}$ We recognize that women are reluctant to report a birth as unwanted retrospectively and as such unwanted births are under-reported retrospectively. However, it is quite likely that some of these births are reported as mistimed. Thus, the degree of under-reporting a birth as unintended (unwanted and mistimed) retrospectively is likely to be less than reporting it as unwanted.
} 
by the third group. The indicator of success is estimated by taking percentages. There are several limitations in using this outcome indicator as reflecting only the quality of care provided by the program (Jain 2017b). For example, the availability and use of abortion, especially medical abortion, in a country will reduce the likelihood of an unwanted pregnancy resulting in a live birth. Furthermore, the likelihood of a birth being reported as unintended may also depend upon the fertility norms prevalent in a society. Table 4 shows estimates of success for 30 countries.

\section{NATIONAL INDICATOR OF QUALITY}

A new National Quality Composite Index (NQCl) to measure quality at the national level is proposed by Jain (2017b). This index can be used to study differences among countries and to monitor quality overtime in a country. The $\mathrm{NQCl}$ is estimated by taking an average of three separate indicators of structure, process, and outcome (AIS) measured by method Availability, method Information, and method Success, respectively. The method Availability indicator is estimated from the latest family planning effort (FPE) survey by taking the average of 10 items about the availability of condom, emergency contraception, pill, injectable, IUD, implant, male sterilization, female sterilization, and availability of services for the removal on demand of IUDs and implants. Method information is measured by MII and method Success by the indicator of Success. These two indicators have been described above. Table 4 shows the data for 30 countries. Other details related to this indicator can be found elsewhere (Jain 2017b).

\section{SUMMARY}

Although the quality of care framework was articulated over 25 years ago and considerable progress has been made since then on the measurement of quality, we do not have an agreed upon indicators to measure quality that can be applied uniformly across different country and health systems. The work done so far has reflected the range and types of data available and the context of the service delivery environments available to the investigators.

We have taken a slightly different approach and used a common definition of quality. The indicators of quality are required for describing the nature of family planning services and quality of care offered by a service delivery program, and for improving quality of care received by clients. Additionally, indicators are needed for monitoring quality overtime within a country's health system and comparing quality delivered and received across countries. Different types of indicators are needed to serve these different needs. Keeping these diverse needs in mind, we propose a set of measures to assess quality which is based on Donabedian's framework of structure, process, and outcome (see Figure 2).

WHO (2017) proposed four indicators of quality among 20 indicators available to support monitoring of human rights in contraceptive services programs. These include informed choice, facilities meeting quality of care standards, presence of national laws, regulations, or policies regulating female and male sterilization, and contraceptive user satisfaction with services. Except for the indicator on the presence of national laws, the other three indicators overlap with the indicators proposed in this paper. For example, informed choice is the same as MII, facilities meeting quality of care standards is a summary indicator that is equivalent to overall indicator of SDP readiness proposed in this paper, and user satisfaction with services is included as an outcome indicator above.

Four SDP readiness domains and overall indicator of SDP readiness proposed above are useful to describe the quality of services in a program, to monitor the quality of services overtime, and to accredit SDPs in terms their readiness to offer quality services to a range of clients. Data required to create these indicators would be useful to identify gaps in quality of services and take remedial actions within the appropriate health system elements, e.g. procurement, supply chain, training, supervision, among others. These data can be collected through facility audits and provider interviews. In addition, efforts need to be made to assess the feasibility of incorporating these data in ongoing facility surveys (SPA, PMA 2020), and HMIS which will help to monitor quality of services periodically for focusing on program improvement.

The primary objective of quality of care framework was to draw attention to the quality of care clients receive in a country or health system. The proposed process level indicators can help to assess the level of care clients are receiving in a program. The required data for the MII are collected through facility as well as cross-sectional surveys of clients at the community level which is its attractive feature. The data on 23 items required for creating other four process indicators can be collected through special and ongoing facility surveys. This type of detailed data cannot be collected with any reliability through cross-sectional surveys. Further research is required to validate the $\mathrm{MII}$ and to assess if the three items included in current MII be expanded by one or two items such as whether women using a reversible method were told about the possibility of switching the method to reflect other key elements of the service giving process and for which data can also be collected with some accuracy through cross-sectional surveys.

Outcome indicators are useful in assessing the effect of quality of care received on client's subsequent behavior. The first two indicators reflect immediate outcome and the remaining two reflect longer-term outcomes. Data required to calculate these outcome indicators can be collected prospectively through longitudinal studies of clients receiving services from facilities as well as retrospectively from women included in cross-sectional surveys.

The proposed $\mathrm{NQCl}$ indicator is useful in comparing quality among countries and monitoring quality in the delivery of care overtime in a country. This index uses the best available 


\section{SDP READINESS (QUALITY OF SERVICES)}

Domains:

- Offer choice (number and

type) of contraceptive

methods

- Ensure safety and

compliance with infection

prevention practices

- Ensure appropriate client

provider interactions

- Offer other appropriate RH \&

$\mathrm{MCH}$ information and

services

Overall SDP readiness

indicator of quality
PROCESS (QUALITY OF CARE)

Domains:

- Respectful care

- Method selection

- Effective use of method

chosen

- Continuity of care

Summary indicators

Overall quality of care index

Method Information Index

\section{OUTCOME}

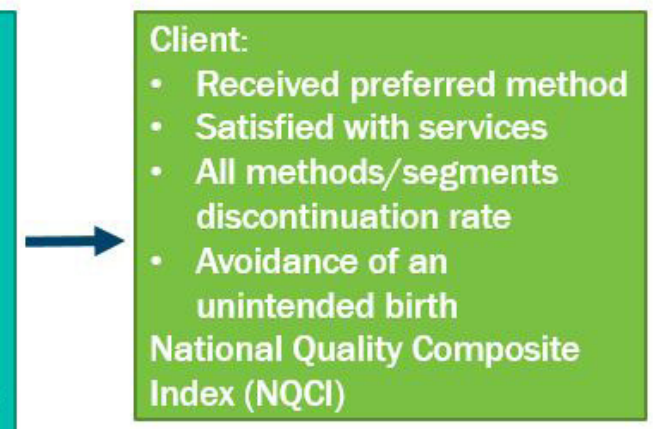

Citation: Jain, Townsend, \& Ramarao, 2018. Proposed metrics to measure quality: Overview. Population Council, NY.

data for structure, process, and outcome indicators. Further research is required to validate and refine these indicators enhancing their metric profile, and to create other national level indicators of quality by using data being collected through SPA and PMA2020.

\section{WAY FORWARD}

Facility surveys are the main data source to calculate the proposed structure and process indicators. While these indicators can be used to guide special studies in the future, efforts need to be made to assess: 1) the extent to which they can be calculated from ongoing SPA and PMA2020 surveys data and 2) the extent to which some of the required data can be incorporated in these surveys. Moreover, the feasibility of incorporating the data required for the SDP readiness indicators in HMIS need to be assessed. Further research is also required to assess the domains of quality of care process.

The data required to calculate MII is collected in almost all facility and cross-sectional surveys. Efforts need to be made to validate this indicator as well as to assess the extent to which these three questions represent the key components of quality of care process and to assess the feasibility of adding one or two additional questions such as whether the users of reversible methods were told about the possibility of switching.

Additional research is required to define and measure the satisfaction indicator of outcome. The possibility of incorporating the method success indicator of outcome or the proposed $\mathrm{NQCl}$ index among the core indicators to measure quality needs to be explored.

The measurement of quality has been a critical, albeit elusive, element of efforts to improve health care globally. As efforts for Universal Health Coverage evolve, the measure of quality must be part of the discussion about it focus, its costs and ultimately the benefit it brings to both health systems and the clients they are committed to serve.

\section{REFERENCES}

1. Ali, Mohamed M., John G. Cleland, and lqbal H. Shah. 2012. "Causes and consequences of contraceptive discontinuation: evidence from 60 demographic and health surveys."

2. Askew I, Mensch B, Adewuyi A. Indicators for measuring the quality of family planning services in Nigeria. Studies in family Planning. 1994 Sep 1; 25(5):268-83.

3. Barden-O'Fallon, J. and Ilene Speizer (2011) What Differentiate Method Stoppers from Switchers? Contraceptive Discontinuation and Switching Among Honduran Women. International Perspectives on Sexual and Reproductive Health. 37(1):16-23, doi:10.1363/3701611

4. Blanc, A., Curtis, S. L. \& Croft, T. N. (2002) Monitoring contraceptive continuation: links to fertility outcomes and quality of care. Studies in Family Planning 33(2), 127-140.

5. Bruce, J. 1990. "Fundamental Elements of the Quality of Care: A Simple Framework”. Studies in Family Planning 21, 2: 61-91

6. Clark Heather, Saumya RamaRao, Kazuyo Machiyama, and Nandita Thatte. 2017. "Expanding Contraceptive Choice." Evidence Brief. http://www.popcouncil.org/uploads/pdfs/ FP_Evidence_method_mix_FINAL_07.10.17.pdf 
7. Costello, M., Lacuesta, M., RamaRao, S. \& Jain, A. (2001) A client-centered approach to family planning: the Davao Project. Studies in Family Planning 32(4), 302-314.

8. Donabedian A. The quality of care: How can it be assessed? Journal of the American Medical Association. 1988. 260, 12 : 1743-1748.

9. FP2020. Commitment to Action, Measurement Annex, November. 2014. Available from: http://progress. familyplanning2020.org/uploads/03/00/FP2020_ MeasurementAnnex_2015_PrinterFriendly.pdf

10. Jain, Anrudh and Judith Bruce. 1994 A Reproductive Health Approach to the Objectives and Assessment of Family Planning Programs. In Population Policies Reconsidered: Health, Empowerment and Rights. Eds. Sen G, Germaine A, and Chen L. Boston: Harvard University Press. Pp. 193-209.

11. Jain, AK. 2001. Implications for Evaluating the Impact of Family Planning Programs with a Reproductive Health Orientation. Studies in Family Planning, 32(3): 220-229.

12. Jain Anrudh, Judith Bruce, and Barbara Mensch.1992. "Setting Standards of Quality in Family Planning Programs." Studies in Family Planning 23(6):392-395.

13. Jain, Anrudh K., Saumya RamaRao, Jacqueline Kim, and Marilou Costello. 2012. "Evaluation of an intervention to improve quality of care in family planning programme in the Philippines." Journal Of biosocial science 44, no. 01: 27-41.

14. Jain AK. Examining progress and equity in information received by women using a modern method in 25 developing countries. International Perspectives on Sexual and Reproductive Health, 2016: 42(3): 131-140.

15. Jain Anrudh K. 2017a. "Quality of Care in the Context of Rights-Based Family Planning." Policy Brief of the Measuring and Monitoring Quality of Services and Quality of Care Project. New York: Population Council. http://www.popcouncil.org/ uploads/pdfs/2017RH_QoCRightsBasedFP.pdf

16. Jain Anrudh K. 2017b. "A New Composite Index to Measure National Level Quality in Family Planning." Manuscript under review. New York: The Population Council.

17. Koenig, M. A., Hossain, M. B. \& Whittaker, M. (1997) The influence of quality of care upon contraceptive use in rural Bangladesh. Studies in Family Planning 28(4), 278-289.

18. Mallick, Lindsay, Wenjuan Wang, and Gheda Temsah. A comparison of summary measures of quality of service and quality of care for family planning in Haiti, Malawi, and Tanzania. DHS Methodological Report No. 20. Rockville, Maryland, USA: ICF.

19. Mensch, B., Fisher, A., Askew, I. \& Ajayi, A. (1994) Using situation analysis data to assess the functioning of family planning clinics in Nigeria, Tanzania, and Zimbabwe. Studies in Family Planning 25(1), 18-31.

20. Mensch, B. S., Arends-Kuenning, M., Jain, A. \& Garate, M. R. (1997). Avoiding unintended pregnancy in Peru: does the quality of family planning services matter? International Family Planning Perspectives 23(1), 21-27

21. Miller, Kate, Robert Miller, lan Askew, Marjorie Horn, Lewis Ndhlovue. 1998. Clinic-Based Family Planning and Reproductive Health Services in Africa: Findings from Situation Analysis Studies. New York: Population Council

22. Miller, Robert A., Lewis Ndhlovu, Margaret M. Gachara, Andrew A. Fisher. 1991. The Situation Analysis Study of the Family Planning Program in Kenya. Studies in Family Planning 22(3), 131-143.
23. Pariani, S., Heer, D. M. \& Van Arsdol, M. D. Jr (1991) Does choice make a difference to contraceptive use? Evidence from East Java. Studies in Family Planning 22(6), 384-390.

24. RamaRao, Saumya and Anrudh K. Jain. 2016. "Constructing indicators for measurement and improvement of the quality of family planning programs: An example using data on choice from the Philippines, 1997-1998." In Quality Measurement of Family Planning: Past, Present, Future: Papers from the Bellagio Meeting on Family Planning Quality in October 2015. (Eds.) Susannah Hopkins Leisher, Andrea Sprockett, Kim Longfield, and Dominic Montague. Oakland CA: Metrics for Management: 47-60.

25. RamaRao, Saumya, Marlina Lacuesta, Marilou Costello, Blesilda Pangolibay, and Heidi Jones. 2003. "The link between quality of care and contraceptive use." International Family Planning Perspectives 29(2): 76-83.

26. Sathar, Zeba, Anrudh Jain, Saumya Rama Rao, Minhaj Haque, and Jacqueline Kim. 2005. "Introducing Client-centered Reproductive Health Services in a Pakistani Setting." Studies in Family Planning 36, no. 3: 221-234.

27. Sullivan TM, Bertrand JT. Monitoring Quality of Care in Family Planning by the Quick Investigation of Quality (QIQ): Country Reports. Evaluation. 1999 Apr.

28. Tessema Gizachew Assefa et al. 2016. "Client and facility level determinants of quality of care in family planning services in Ethiopia: Multilevel modelling. PLOS ONE 12(6): e0179167. https://doi.org/10.1371/journal.pone.0179167

29. Tumlison K. et al. 2015. Quality of care and contraceptive use in urban Kenya. International Perspective on Sexual and Reproductive Health 41(2):69-79.

30. Tumlinson Katherine. 2016. "Measuring Quality of Care: A Review of Previously Used Methodologies and Indicators." Working Paper Two of the Measuring and Monitoring Quality of Services and Quality of Care Project. New York: Population Council. http://www.popcouncil.org/uploads/pdfs/2016RH_ MeasuringQ0C_wp2.pdf

31. Wang, Wenjuan, Mai do, John Hembling, Paul Ametepi. 2014. Assessing the Quality of Care in Family Planning, Antenatal, and Sick Child Services at Health Facilities in Kenya, Namibia, and Senegal. DHS Analytical Studies No. 44

32. WHO (2017). Monitoring human rights in contraceptive services and programs. Geneva: World Health Organization. http://apps.who.int/iris/bitstre am/10665/259274/1/9789241513036-eng.pdf?ua=1 (accessed 12.11.2017).

\section{ACKNOWLEDGMENTS}

The authors gratefully acknowledge the support and encouragement of the David and Lucile Packard Foundation to the Population Council to continue research on the current state of quality of care. Comments can be sent to the first author at ajain@popcouncil.org.

Suggested citation: Jain Anrudh K., John Townsend, and Saumya RamaRao. 2018. Proposed metrics to measure quality: An overview. Working Paper no. 3, prepared for the Measuring and Monitoring Quality of Care Project. New York: Population Council. 


\section{Table 1: Items included in structure (SDP readiness ${ }^{*}$ ) indicators of quality in previous facility surveys}

\begin{tabular}{|c|c|c|c|c|c|c|}
\hline \multirow[b]{2}{*}{ Items describing SDP structure } & \multicolumn{5}{|c|}{ Facility audits } & \multirow{2}{*}{ HMIS } \\
\hline & SA & QIQ & SPA & $\begin{array}{l}\text { MLE } \\
2020\end{array}$ & PMA & \\
\hline Infrastructure and Facilities & & & $\sqrt{ }$ & & & \\
\hline Has electricity & $\sqrt{ }$ & & & & & \\
\hline Has piped running water & $\sqrt{ }$ & & & & & \\
\hline Has working toilets for clients & $\sqrt{ }$ & & & & & \\
\hline \multicolumn{7}{|l|}{ Has handwashing station for staff } \\
\hline \multicolumn{7}{|l|}{ Accessibility } \\
\hline Opens on time & $\sqrt{ }$ & & & & & \\
\hline Has sign announcing FP services & $\sqrt{ }$ & & & & & \\
\hline Number of days FP offered & & & & & $\sqrt{ }$ & \\
\hline Methods offered and stock outs & & & $\sqrt{ }$ & & $\sqrt{ }$ & \\
\hline Methods available & $\sqrt{ }$ & $\sqrt{ }$ & $\sqrt{ }$ & $\sqrt{ }$ & $\sqrt{ }$ & \\
\hline No stock out & $\sqrt{ }$ & $\sqrt{ }$ & & $\sqrt{ }$ & $\sqrt{ }$ & \\
\hline Has commodity inventory list & $\sqrt{ }$ & & & & & \\
\hline Has adequate storage of for contraceptive stocks & $\sqrt{ }$ & $\sqrt{ }$ & & & & \\
\hline \multicolumn{7}{|l|}{ Equipment } \\
\hline Has basic equipment (multiple items) & $\sqrt{ }$ & $\sqrt{ }$ & & $\sqrt{ }$ & $@$ & \\
\hline \multicolumn{7}{|l|}{ Staffing } \\
\hline Type of staff providing services & $\sqrt{ }$ & & & & & \\
\hline Experience of staff & $\sqrt{ }$ & & & & & \\
\hline Basic and refresher training of staff & $\sqrt{ }$ & & $\sqrt{ }$ & & @ & \\
\hline \multicolumn{7}{|l|}{ IEC materials } \\
\hline Has IEC materials on family planning, STD, HIV & $\sqrt{ }$ & & & & & \\
\hline Group health talks cover FP, STD, HIV & $\sqrt{ }$ & & & & & \\
\hline \multicolumn{7}{|l|}{ Recordkeeping and Supervision } \\
\hline Has clinical record cards & $\sqrt{ }$ & & & & & \\
\hline Had supervisory visit in last 6 months & $\sqrt{ }$ & $\sqrt{ }$ & $\sqrt{ }$ & & $\sqrt{ }$ & \\
\hline Privacy for pelvic examination/IUD insertion & & $\sqrt{ }$ & & & $\sqrt{ }$ & \\
\hline Waiting time acceptable & & $\sqrt{ }$ & & & & \\
\hline Mechanism to make programmatic changes & & $\sqrt{ }$ & & & & \\
\hline System to obtain client feedback & & & $\sqrt{ }$ & & $\sqrt{ }$ & \\
\hline Guidelines for FP services & & & $\sqrt{ }$ & $\sqrt{ }$ & & \\
\hline Quality assurance measures in place & & & $\sqrt{ }$ & & & \\
\hline FP integrated with child health, postpartum, HIV & & & $\sqrt{ }$ & & & \\
\hline Adolescent and post abortion services & & & & & $\sqrt{ }$ & \\
\hline
\end{tabular}

* See text for recommended indicators of SDP readiness; @. Partially available. 


\begin{tabular}{|c|c|c|c|c|c|c|}
\hline \multirow[t]{2}{*}{ Domains of process indicator } & \multicolumn{4}{|c|}{ Facility-based exit interview } & \multicolumn{2}{|c|}{$\begin{array}{l}\text { Cross- } \\
\text { sectional } \\
\text { survey }\end{array}$} \\
\hline & Proposed & QIQ & SPA & MLE & DHS & $\begin{array}{l}\text { PMA } \\
2020\end{array}$ \\
\hline \multicolumn{7}{|l|}{ Domains of Process indicator of quality } \\
\hline \multicolumn{7}{|l|}{ 1. Respectful care } \\
\hline Respondent allowed to ask questions & $\sqrt{ }$ & & $\sqrt{ }$ & $\sqrt{ }$ & & \\
\hline Questions answered to her satisfaction & $\sqrt{ }$ & & & & & \\
\hline Provider was friendly & $\sqrt{ }$ & & & $\sqrt{ }$ & & \\
\hline Provider was respectful & $\sqrt{ }$ & & & & & \\
\hline Respondent felt her privacy was protected & $\sqrt{ }$ & & $\sqrt{ }$ & & & \\
\hline Respondent felt her confidentiality was protected & $\sqrt{ }$ & & $\sqrt{ }$ & & & \\
\hline \multicolumn{7}{|l|}{ 2. Method selection } \\
\hline \multicolumn{7}{|l|}{ Respondent } \\
\hline Was asked if she desired another child & $\sqrt{ }$ & $\sqrt{ }$ & $\sqrt{ }$ & $\sqrt{ }$ & & \\
\hline Was asked her preferred timing of the next child & $\sqrt{ }$ & $\sqrt{ }$ & $\sqrt{ }$ & & & \\
\hline Was asked her previous family planning experience & $\sqrt{ }$ & & & & & \\
\hline $\begin{array}{l}\text { Was asked about characteristics or name of her } \\
\text { preferred method }\end{array}$ & $\sqrt{ }$ & $\sqrt{ }$ & $\sqrt{ }$ & $\sqrt{ }$ & & \\
\hline Was told about other methods & $\sqrt{ }$ & & $\sqrt{ }$ & $\sqrt{ }$ & $\sqrt{ }$ & $\sqrt{ }$ \\
\hline $\begin{array}{l}\text { Received information about methods that protect } \\
\text { against STIs }\end{array}$ & $\sqrt{ }$ & $\sqrt{ }$ & $\sqrt{ }$ & & & \\
\hline Received information without any method being promoted & $\sqrt{ }$ & & & & & \\
\hline Received chosen method & $\sqrt{ }$ & $\sqrt{ }$ & & & & $\sqrt{ }$ \\
\hline \multicolumn{7}{|l|}{ 3. Effective use of the method selected } \\
\hline \multicolumn{7}{|l|}{ Respondent was given information about: } \\
\hline How her chosen method works & $\sqrt{ }$ & & $\sqrt{ }$ & & & \\
\hline How to use the method & $\sqrt{ }$ & $\sqrt{ }$ & $\sqrt{ }$ & $\sqrt{ }$ & & \\
\hline Side effects of the method & $\sqrt{ }$ & $\sqrt{ }$ & $\sqrt{ }$ & $\sqrt{ }$ & $\sqrt{ }$ & $\sqrt{ }$ \\
\hline How to manage problems & $\sqrt{ }$ & $\sqrt{ }$ & $\sqrt{ }$ & $\sqrt{ }$ & $\sqrt{ }$ & $\sqrt{ }$ \\
\hline Warning signs associated with method & $\sqrt{ }$ & $\sqrt{ }$ & & & & \\
\hline \multicolumn{7}{|l|}{ 4. Continuity of contraceptive use and care } \\
\hline \multicolumn{7}{|l|}{ Respondent was told about: } \\
\hline Told about timing of next visit & $\sqrt{ }$ & $\sqrt{ }$ & $\sqrt{ }$ & $\sqrt{ }$ & & \\
\hline Given an appointment card for follow-up visit & $\sqrt{ }$ & & & & & \\
\hline Possibility of switching the method & $\sqrt{ }$ & & & & & \\
\hline Told about other sources of supply & $\sqrt{ }$ & & & & & \\
\hline \multicolumn{7}{|l|}{ Process indicator of quality ${ }^{@}$} \\
\hline Method Information Index & $\sqrt{ }$ & & $\sqrt{ }$ & $\sqrt{ }$ & $\sqrt{ }$ & $\sqrt{ }$ \\
\hline
\end{tabular}

@ To be constructed from items specified above 
Table 3: Values of the National Quality Composite Index (NQCI) and its Components by Country and

Region

\begin{tabular}{|c|c|c|c|c|c|}
\hline \multirow[b]{2}{*}{ Country } & \multirow[b]{2}{*}{ Year } & \multicolumn{3}{|c|}{ Components of NQCl } & \multirow[b]{2}{*}{$\mathrm{NQCl}$} \\
\hline & & $\begin{array}{c}\text { Method } \\
\text { Availability }\end{array}$ & $\begin{array}{c}\text { Method } \\
\text { Information }\end{array}$ & $\begin{array}{l}\text { Method } \\
\text { Success }\end{array}$ & \\
\hline SSA & $2008-14$ & 52.2 & 43.6 & 83.5 & 59.8 \\
\hline Rwanda & 2010-11 & 73.2 & 57.7 & 82.1 & 71.0 \\
\hline Benin & 2011-12 & 59.9 & 45.0 & 91.7 & 65.6 \\
\hline Senegal & 2014 & 65.4 & 41.4 & 85.3 & 64.1 \\
\hline Zambia & 2013-14 & 42.1 & 71.0 & 76.3 & 63.1 \\
\hline Tanzania & 2010 & 52.1 & 51.5 & 85.0 & 62.8 \\
\hline Mozambique & 2011 & 45.5 & 53.6 & 89.3 & 62.8 \\
\hline Madagascar & 2008 & 47.9 & 45.1 & 95.3 & 62.8 \\
\hline Malawi & 2010 & 50.5 & 64.6 & 70.3 & 61.8 \\
\hline Nigeria & 2013 & 39.6 & 50.2 & 88.4 & 59.4 \\
\hline Kenya & $2008-09$ & 53.3 & 43.2 & 80.2 & 58.9 \\
\hline Namibia & 2013 & 49.1 & 40.8 & 85.8 & 58.6 \\
\hline Ghana & 2008 & 50.3 & 41.9 & 80.1 & 57.5 \\
\hline Zimbabwe & 2010-11 & 53.7 & 35.9 & 81.8 & 57.1 \\
\hline Niger & 2012 & 49.4 & 28.5 & 89.8 & 55.9 \\
\hline Uganda & 2011 & 48.6 & 43.9 & 75.1 & 55.9 \\
\hline Lesotho & 2009 & 45.2 & 27.8 & 90.9 & 54.6 \\
\hline Burundi & 2010 & 58.4 & 26.3 & 75.2 & 53.3 \\
\hline Ethiopia & 2011 & 54.8 & 17.1 & 80.7 & 50.9 \\
\hline Non-SSA & 2004-14 & 52.3 & 36.2 & 90.3 & 59.6 \\
\hline Cambodia & 2010 & 57.9 & 63.9 & 94.6 & 72.1 \\
\hline Jordan & 2012 & 61.5 & 49.3 & 82.2 & 64.3 \\
\hline Nepal & 2011 & 54.0 & 42.2 & 96.7 & 64.3 \\
\hline Bolivia & 2008 & 49.9 & 51.4 & 82.9 & 61.4 \\
\hline Egypt & 2014 & 53.9 & 38.1 & 88.7 & 60.3 \\
\hline Peru & 2012 & 43.5 & 52.4 & 84.2 & 60.0 \\
\hline Timor Leste & $2009-10$ & 37.0 & 40.2 & 97.5 & 58.2 \\
\hline Bangladesh & 2004 & 67.1 & 19.5 & 87.5 & 58.1 \\
\hline Indonesia & 2012 & 54.7 & 20.9 & 94.0 & 56.5 \\
\hline Honduras & 2011-12 & 52.9 & 28.2 & 87.2 & 56.1 \\
\hline India & 2005-06 & 49.0 & 15.6 & 98.7 & 54.4 \\
\hline Pakistan & 2012-13 & 45.9 & 13.2 & 89.8 & 49.7 \\
\hline Total & 2004-14 & 52.2 & 40.7 & 86.2 & 59.7 \\
\hline
\end{tabular}

$\mathrm{NQCl}=($ Availability + Information + Success $) / 3 ;$ SSA: Sub Saharan Africa

Source: Jain (2017b) 


\section{APPENDIX I}

\section{Quality of Care: Definition and Assessment Tool ${ }^{4}$}

Family planning program managers in most countries do intend to provide services of high quality. We understand that political realities and resource constraints must be considered while implementing their desire to provide services of high quality and to plan improvements in a logical sequence. The definition of high quality may itself vary from setting to setting. We would like your assistance in identifying important attributes of high quality programs that are relevant in your setting.

To achieve this objective, we have identified a set of attributes that may be used to define a program of high quality. Two questions are asked for each attribute. The first question refers to the emphasis or importance a program should place and the second question refers to the emphasis your program actually places on a particular attribute. Please feel free to circle 0 if a particular attribute is not relevant in your setting or if your program places no emphasis on it. Please circle 3 if a particular attribute is most important or if your program places most emphasis on it. Please feel free to add any other attributes(s) that you think are most important for a high-quality family planning program.

A. How much emphasis should family planning programs place on the attributes included in the enclosed table?

0. No emphasis

1. Minor emphasis

2. Moderate emphasis

3. Considerable emphasis

B. How much emphasis does your program actually place on the attributes included in the enclosed table?

0. No emphasis

1. Minor emphasis

2. Moderate emphasis

${ }^{4}$ For soliciting family planning program managers' perspectives 


\begin{tabular}{|c|c|c|c|c|c|c|c|c|}
\hline \multirow{3}{*}{$\begin{array}{l}\text { Attributes of Family Planning Programs of High Quality } \\
\text { 1. a. Providing an appropriate choice of methods to all clients } \\
\text { b. Not promoting any particular method }\end{array}$} & \multicolumn{4}{|c|}{ Ideal emphasis } & \multicolumn{4}{|c|}{ Actual emphasis } \\
\hline & 0 & 1 & 2 & 3 & 0 & 1 & 2 & 3 \\
\hline & 0 & 1 & 2 & 3 & 0 & 1 & 2 & 3 \\
\hline c. Not restricting any particular method & 0 & 1 & 2 & 3 & 0 & 1 & 2 & 3 \\
\hline $\begin{array}{l}\text { 2. Ensuring that providers are technically competent in: } \\
\text { a. Screening clients for contraindications }\end{array}$ & 0 & 1 & 2 & 3 & 0 & 1 & 2 & 3 \\
\hline b. Supplying 'clinical' methods & 0 & 1 & 2 & 3 & 0 & 1 & 2 & 3 \\
\hline c. Applying effective aseptic techniques & 0 & 1 & 2 & 3 & 0 & 1 & 2 & 3 \\
\hline $\begin{array}{l}\text { 3. Ensuring that each client receives information about: } \\
\text { a. Method options appropriate to her needs }\end{array}$ & 0 & 1 & 2 & 3 & 0 & 1 & 2 & 3 \\
\hline b. Contraindication of method selected & 0 & 1 & 2 & 3 & 0 & 1 & 2 & 3 \\
\hline c. Common side effects of method selected & 0 & 1 & 2 & 3 & 0 & 1 & 2 & 3 \\
\hline d. How to manage their side effects & 0 & 1 & 2 & 3 & 0 & 1 & 2 & 3 \\
\hline e. Follow up requirements of method selected & 0 & 1 & 2 & 3 & 0 & 1 & 2 & 3 \\
\hline f. Duration of effective use of method selected & 0 & 1 & 2 & 3 & 0 & 1 & 2 & 3 \\
\hline g. Possibility of switching the method if preferred & 0 & 1 & 2 & 3 & 0 & 1 & 2 & 3 \\
\hline h. Possibility of switching the source of supply & 0 & 1 & 2 & 3 & 0 & 1 & 2 & 3 \\
\hline $\begin{array}{l}\text { 4. Ensuring that providers assist the client in selecting a } \\
\text { method by soliciting information from clients about her: } \\
\text { a. Background (age, number of children) }\end{array}$ & 0 & 1 & 2 & 3 & 0 & 1 & 2 & 3 \\
\hline b. Reproductive goals (timing of next desired child) & 0 & 1 & 2 & 3 & 0 & 1 & 2 & 3 \\
\hline c. Attitudes and preferences for contraceptive methods & 0 & 1 & 2 & 3 & 0 & 1 & 2 & 3 \\
\hline d. Prior experience with contraceptive methods & 0 & 1 & 2 & 3 & 0 & 1 & 2 & 3 \\
\hline $\begin{array}{l}\text { 5. Ensuring that a client makes a specific appointment for a } \\
\text { follow up visit or a specific plan for resupply with the } \\
\text { provider }\end{array}$ & 0 & 1 & 2 & 3 & 0 & 1 & 2 & 3 \\
\hline $\begin{array}{l}\text { 6. Ensuring that clients receive visual and physical privacy } \\
\text { during: } \\
\text { a. Personal interview and information sharing }\end{array}$ & 0 & 1 & 2 & 3 & 0 & 1 & 2 & 3 \\
\hline b. Physical examination/method provision & 0 & 1 & 2 & 3 & 0 & 1 & 2 & 3 \\
\hline $\begin{array}{l}\text { 7. Ensuring that providers treat clients with dignity and } \\
\text { respect }\end{array}$ & 0 & 1 & 2 & 3 & 0 & 1 & 2 & 3 \\
\hline 8. Other (please specify): & 0 & 1 & 2 & 3 & 0 & 1 & 2 & 3 \\
\hline
\end{tabular}

